University of Wollongong

Research Online

Faculty of Engineering and Information

Faculty of Engineering and Information

Sciences - Papers: Part A

Sciences

$1-1-2013$

\title{
Microtexture based analysis of surface asperity flattening behavior of annealed aluminum alloy in uniaxial planar compression
}

\author{
Hejie Li \\ University of Wollongong, hejie@uow.edu.au \\ Zhengyi Jiang \\ University of Wollongong, jiang@uow.edu.au \\ Dongbin Wei \\ University of Wollongong, dwei@uow.edu.au \\ Xiaoming Zhang \\ Northeastern University China
}

Follow this and additional works at: https://ro.uow.edu.au/eispapers

Part of the Engineering Commons, and the Science and Technology Studies Commons

\footnotetext{
Research Online is the open access institutional repository for the University of Wollongong. For further information
} contact the UOW Library: research-pubs@uow.edu.au 


\title{
Microtexture based analysis of surface asperity flattening behavior of annealed aluminum alloy in uniaxial planar compression
}

\author{
Abstract \\ During the uniaxial planar compression of annealed aluminum alloy, a novel approach to determine \\ surface asperity flattening (roughness $\mathrm{Ra}$ ) is employed by analyzing the evolution of surface microtexture. \\ With an increase in gauged reduction, surface asperity tends to be flattened, and strain hardening \\ increases. Lubrication can constrain the surface asperity flattening process. Development of surface \\ asperity features shows the obvious dependency on [111] orientation. In-grain slips contribute \\ significantly to the evolution of surface microtexture. Influence of deformation twins (brass orientation) \\ on the evolution of microtexture is not obvious under our current experimental conditions.

\section{Keywords} \\ planar, uniaxial, alloy, aluminum, annealed, compression, behavior, microtexture, flattening, asperity, \\ surface, analysis

\section{Disciplines} \\ Engineering | Science and Technology Studies

\section{Publication Details} \\ Li, H., Jiang, Z., Wei, D. \& Zhang, X. (2013). Microtexture based analysis of surface asperity flattening \\ behavior of annealed aluminum alloy in uniaxial planar compression. Tribology International, 66 282-288.
}




\title{
Microtexture Based Analysis of Surface Asperity Flattening Behavior of Annealed Aluminum Alloy in Uniaxial Planar Compression
}

\author{
Hejie $\mathrm{Li}^{\mathrm{a}}$, Zhengyi Jiang ${ }^{\mathrm{a}, *}$, Dongbin $\mathrm{Wei}^{\mathrm{a}}$, Xiaoming Zhang ${ }^{\mathrm{b}}$ \\ a School of Mechanical, Materials and Mechatronic Engineering, University of Wollongong, New South Wales 2522, \\ Australia \\ ${ }^{\mathrm{b}}$ State Key Laboratory of Rolling and Automation, Northeastern University, Shenyang, Liaoning 110004, China
}

jiang@uowmail.edu.au

\begin{abstract}
During the uniaxial planar compression of annealed aluminum alloy, a novel approach to determine surface asperity flattening (roughness $R_{a}$ ) is employed by analyzing the evolution of surface microtexture. With an increase in gauged reduction, surface asperity tends to be flattened, and strain hardening increases. Lubrication can constrain the surface asperity flattening process. Development of surface asperity features shows the obvious dependency on [111] orientation. Ingrain slips contribute significantly to the evolution of surface microtexture. Influence of deformation twins (brass orientation) on the evolution of microtexture is not obvious under our current experimental conditions.
\end{abstract}

Keywords: Surface asperity flattening; Shear band; Atomic Force Microscope (AFM); Electron Back-Scattering Diffraction (EBSD)

\section{Introduction}

Surface roughness is an important parameter for metal products. In plastic deformation, development of surface topology plays an important role in the final surface quality of metal products. Numerous research papers shows that surface evolution is a function of plastic strain, grain size and grain orientation [1-5]. In practical metal forming processes, development of surface topology includes two types of surfaces: free surface and constrained surface. During plastic deformation, unconstrained metal surfaces tend to roughen. Osakada and Oyane [6] found that surface roughening increases with strain, and is greater for coarser grain materials and for metals with a small number of slip systems. Therefore, CPH (close-packed hexagonal) metals roughen most, FCC (face-centered cubic) material less, and BCC (body-centerd cubic) materials the least. Tokizawa and Yosikawa [7] further included the influence of two material phases on the roughening process. Chen et al. [8] found that grain rotation is the most important factor determining surface roughening. Becker [1] established a model to address the influence of inhomogeneities in the deformation by suggesting the unconstrained deformation at the surface causes grain displacements in a direction normal to the surface, and thereby increases the overall surface area. Stoudt and Ricker [9] carried out a tensile experiment on AA5052 alloy, and they demonstrated that the roughening rate $\left(\mathrm{d} R_{a} / \mathrm{d} \varepsilon_{p l}\right)$ is dependent on the grain size, and pointed out that the surface roughening of a polycrystalline material is a highly complex process and results from multiple deformation mechanisms.

On the other hand, most metal forming processes are the processes of constrained surfaces, such as rolling and compression. In these processes, when the tool contacts the sample, it is practically a surface asperity flattening process. Wilson et al. [10, 11] have investigated the effect of bulk plasticity on asperity flattening when the lay of the roughness is parallel to the bulk 
straining direction (longitudinal roughness). They found that the rate of asperity flattening with bulk straining was related to the spacing and pressure of asperities. Makinouchi et al. [12] have employed elastic-plastic finite element solutions for the case of transverse roughness. Wilson and Sheu [13] also found a large increase of contact area with bulk strain and a reduction in the load needed for bulk yielding. Sutcliffe [14] tested and developed Wilson and Sheu's theories, and pointed out that the high pressure between contacting asperities and deformation of bulk material affects the asperity deformation. Dieter [15] found that the inhomogeneous deformation mechanisms that generate the surface roughening also initiate strain localizations which induce necking, tearing, or wrinkling in the component during the forming process. Wilson [11] also points out that the inhomogeneous deformation can accelerate die wear by increasing the friction and abrasion between the metal sheets and the die faces. Groche $[16,17]$ analyzed the surface evolution caused by contact loading in a 2D-plane strain finite element (FEA) model, and established a correlation between the surface topology, grain size and surface evolution.

However, there are few reports studied on the interaction between the surface asperity flattening (roughness), texture and grain orientation. In previous work, we analyzed the relationship between the surface asperity flattening [18], friction [19] and grain size [20] by 2D and 3D crystal plasticity finite element simulations. In order to figure out the relationship between the sample surface asperity flattening, texture and grain orientation, the uniaxial planar compression has been carried out in the INSTRON servo-hydraulic testing machine with different deformation (reduction) and friction conditions (with and without lubricant). As its high multiaxial ductility, a light material-aluminum 6061 alloy is selected as the experimental material in this study. After compression, sample surfaces are measured by Atomic Force Microscope (AFM). Microstructure along the transverse direction is measured by FEG-SEM 7100F. The experimental results show that surface asperities of samples tend to decrease and strain hardening increases with an increase in gauged reduction. Lubrication can constrain the surface asperity flattening process. It is also obtained from the microstructure analysis, a certain crystallographic orientation ([111]) of near-surface grains plays a significant role in the development of the surface roughness. In-grain slip exists under overall reductions. It plays a main role in the development of surface microstructure. A few transgranular slip occurs under a gauged reduction of $60 \%$.

\section{2 . Experimental}

\subsection{Equipment and sample preparation}

After a fully annealed heat treatment $\left(450^{\circ} \mathrm{C}\right.$, $2 \mathrm{~h}$, Fig. 1$)$, aluminium alloy 6061 samples $(10 \mathrm{~mm} \times 10 \mathrm{~mm} \times 6 \mathrm{~mm}$ as shown in Fig. 2c were compressed in a channel die, while samples were constrained in the transverse direction. In order to reduce the influence of tool, the compressing tool is polished smoothly (roughness is about $10 \mathrm{~nm}$ ) and flat. The deformation ranges from 0 to $60 \%$. The compression schedule is shown in Table 1. The compressing channel die includes two parts: compressing mould and tool (Figs. 2a and b). For convenience of handling sample, the compressing mould includes two separate parts which are assembled by a screw. The compression test was carried out by the INSTRON servo-hydraulic testing machine. Strain rate is about $0.001 \mathrm{~s}^{-1}$. 


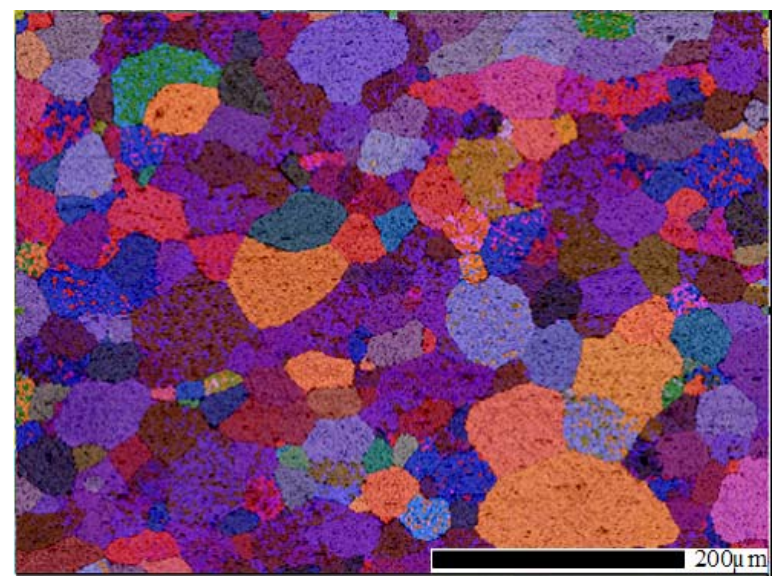

Fig. 1. Microstructure before compression $\left(450^{\circ} \mathrm{C}, 2 \mathrm{~h}\right)$

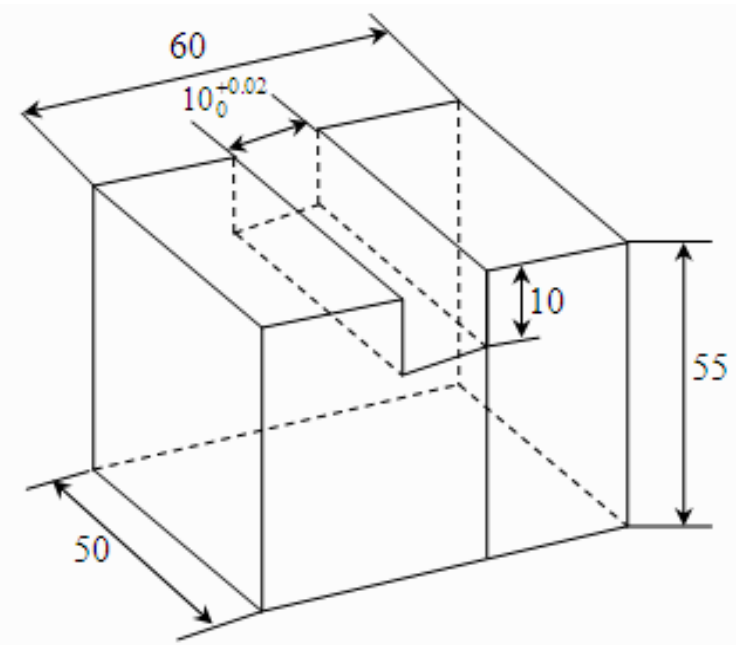

(a)

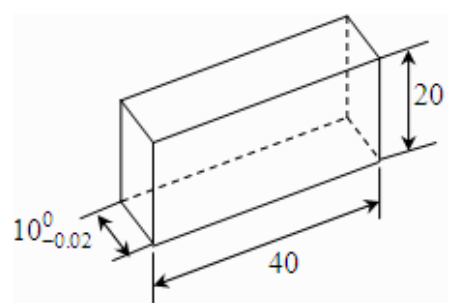

(b)

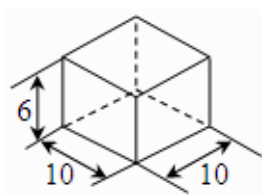

(c)

Fig. 2. Compressing equipment and sample: (a) compressing mold, (b) compressing tool, (c) sample [20]. Unit: mm

Table 1 Parameters for compression

\begin{tabular}{ccccccc}
\hline Samples & $\begin{array}{c}\text { Height } \\
(\mathrm{mm})\end{array}$ & $\begin{array}{c}\text { Reduction } \\
(\%)\end{array}$ & $\begin{array}{c}\text { Strain rate } \\
\left(\mathrm{s}^{-1}\right)\end{array}$ & $\begin{array}{c}\text { Displacement rate } \\
(\mathrm{mm} / \mathrm{min})\end{array}$ & $\begin{array}{c}\text { Displacement } \\
(\mathrm{mm})\end{array}$ & $\begin{array}{c}\text { Height after } \\
\text { compression } \\
(\mathrm{mm})\end{array}$ \\
\hline 1 & 6.3 & 10 & 0.001 & -0.359 & 0.63 & 5.67 \\
2 & 6.3 & 20 & 0.001 & -0.339 & 1.26 & 4.04 \\
3 & 6.3 & 40 & 0.001 & -0.296 & 2.52 & 3.78 \\
4 & 6.3 & 60 & 0.001 & -0.248 & 3.78 & 2.52 \\
\hline
\end{tabular}

The strain rate for the compression is $0.001 \mathrm{~s}^{-1}$. However, for the testing machine, it is difficult to control the strain rate. The displacement rate is thus used to replace the strain rate $[18,20]$. The relationship between the strain rate and displacement rate is

$$
H_{0}=H+\Delta H, \varepsilon=\ln \frac{H}{H_{0}}, \Delta t=\varepsilon / \dot{\varepsilon}, \stackrel{\&}{U}=\Delta H / \Delta t
$$


where $H_{0}, H, \Delta H$ are the original height, the height after compression and the height increment respectively, $\varepsilon$ is the true strain, $\Delta t$ is the time of deformation, and $\dot{U}$ is the displacement rate of sample in the compression.

\subsection{Test of AFM and EBSD and HARDNESS}

AFM and Electron Back-Scattering Diffraction (EBSD) are firstly combined to analyse the relationship between the surface asperity feature and surface texture. The measuring map of cold-planar compressed sample is analyzed by the method shown in Ref [21]. Low-angle grain boundary (LAGB) is defined as $2^{\circ} \leq \theta<15^{\circ}$ where $\theta$ is the angle of grain orientation spread. High-angle grain boundary (HAGB) is defined as $15^{\circ} \leq \theta \leq 62.8^{\circ}$. The threshold of subgrain is $2^{\circ}$. EBSD test was conducted at the mid-section of the samples in normal direction (ND)-rolling direction (RD), step sizes of 0.5 and $0.25 \mu \mathrm{m}$ were employed for the samples with different reductions. The EBSD acquisition is detailed in Ref. [21]. Before and after compressions, sample surface morphology and roughness were measured in the same area by AFM. The AFM maps are scanned by contact mode with the following set of parameters: scan size of $60.00 \mu \mathrm{m}$, scan rate of $1.00 \mathrm{HZ}$ and resolution of 512. The distance between mid-section and surface is only about $400 \mu \mathrm{m}$. When the scanning took place, the scanning area was marked to locate the same area before and after the experiment. Normally, the scanning area is in the centre of midsection which is only several hundred microns from the surface. And the surfaces measured by the AFM and 2D/3D profile meter are also the same area as that scanned by FEG-SEM. The hardness test was carried out on the center area of sample's top surface by the LECO M-400-H1 Micro Hardness Tester with a load of 25 gram and at the room temperature.

\section{Results and discussion}

\subsection{Analysis of surface roughness and hardness}

The schematic of surface asperity deformation is shown in Fig. 3 [21]. A blue line is drawn through the surface nodal coordinates and assumed to be a smooth surface after compression, therefore, the average roughness, $R_{a}$, is determined from

$$
R_{a}=\frac{1}{L} \int_{0}^{l}|\delta| d x
$$

where $L$ represents the length of surface asperity after a certain deformation, and $\delta$ is the distance from this line to the surface nodes $[1,18]$.

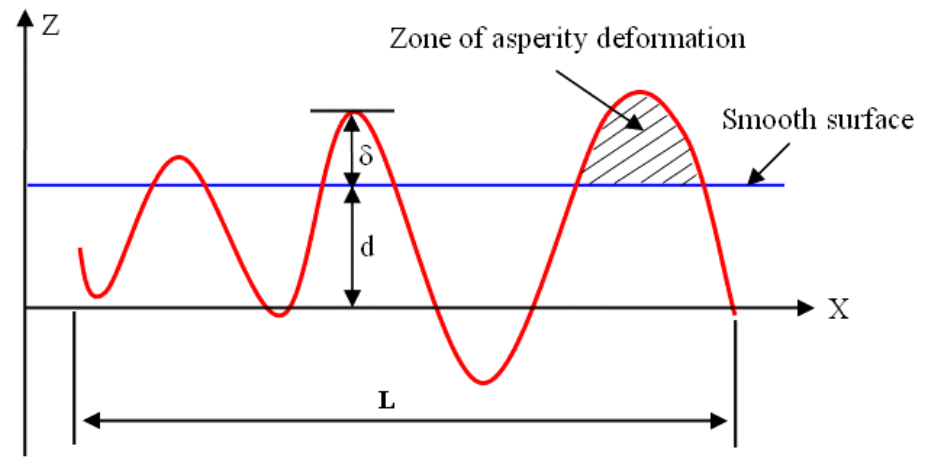

Fig. 3. Schematic of Surface asperity deformation [1] 
Fig. 4 depicts the development of average hardness and surface roughness under different reduction on a basis of experimental results. Average surface roughness is calculated according to the equation (2) and Fig.3. The development of surface morphology under different reductions is shown in Fig. 5. There is an obvious tendency that, with an increase of gauged reduction, the surface asperity (surface roughness) tends to be flattened. Surface asperity flattening includes deformation of contact zone of surface asperity and deformation of no contact area of the sample. First, when the external load is applied onto the sample surface, deformation (including elastic deformation and relatively low plastic deformation) occurs at the contact zone of surface asperity. When deformation takes place, the contact zone of surface asperity decreases from previous $\mathrm{d}+\delta$ to $\delta$. At the same time, the deformation occurs at the non contact area of the sample. If the reduction is small (20\%), the deformation of the surface asperity contact zone is shown in Fig. 5. Under the same reduction there is no significant increase of average Vickers hardness, but after annealing heat treatment, the average Vicker hardness is about 30 HV. Under a reduction of $20 \%$ the average Vicker hardness is about 34 HV (Fig. 4). Strain hardening is not obvious, and the deformation mainly concentrates on the surface asperity contact area (ridge and valley areas) [18]. With an increase in reduction (30 and $40 \%$ ), surface asperity flattening becomes obvious, as shown in Fig. 5 . Although there is an influence of friction between the tool and the sample, the sample surface will be fundamentally flat due to tool effect. Surface slip leads to surface scratches in the area where the contact stress is large and metal flow in different areas is very different. The strain hardening is also significant, as shown in Fig. 4, the average Vickers hardness increases from 34 to 45 HV (reduction $40 \%$ ) and $57 \mathrm{HV}$ (reduction $60 \%$ ). The results reveal that lubrication can constrain the surface asperity flattening [18], as shown in Fig. 5. Under the same reduction, the sample compressed with lubrication is much rougher than that the sample compressed without lubrication. The reason for this is that lubrication can reduce the friction between sample and tool, then the sample can deform freely with less strain hardening. Therefore, influence of the tool surface (which is flat in this study) on sample is not so significant, and sample surface asperity flattening process can be constrained. Due to the similar reason, lubricating condition also plays an important role on the hardness value by effectively reducing the working hardening in the deformation process.

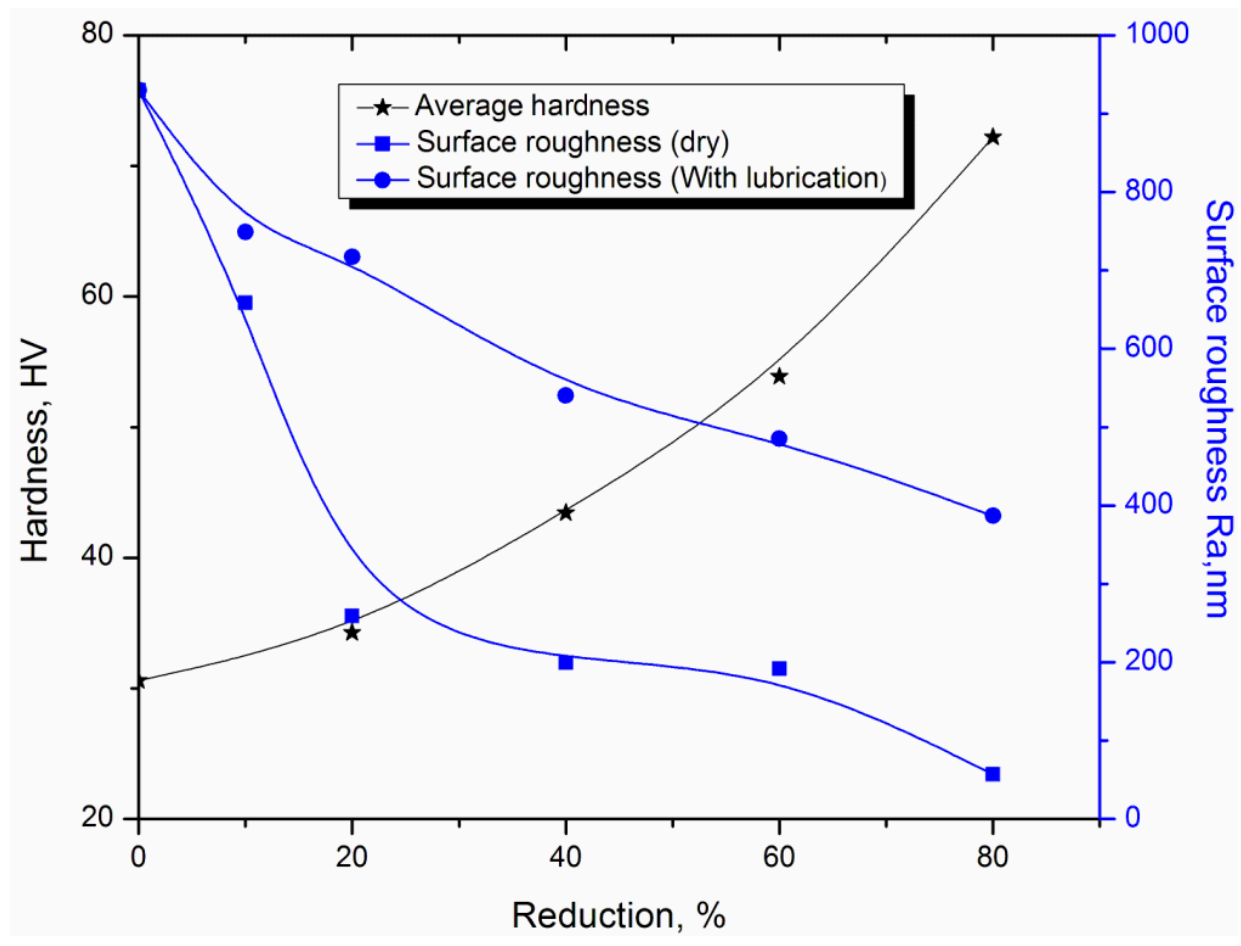

Fig. 4. Hardness development and influence of lubrication on roughness 
Fig. 5. Surface asperity development under different reductions with and without lubrication

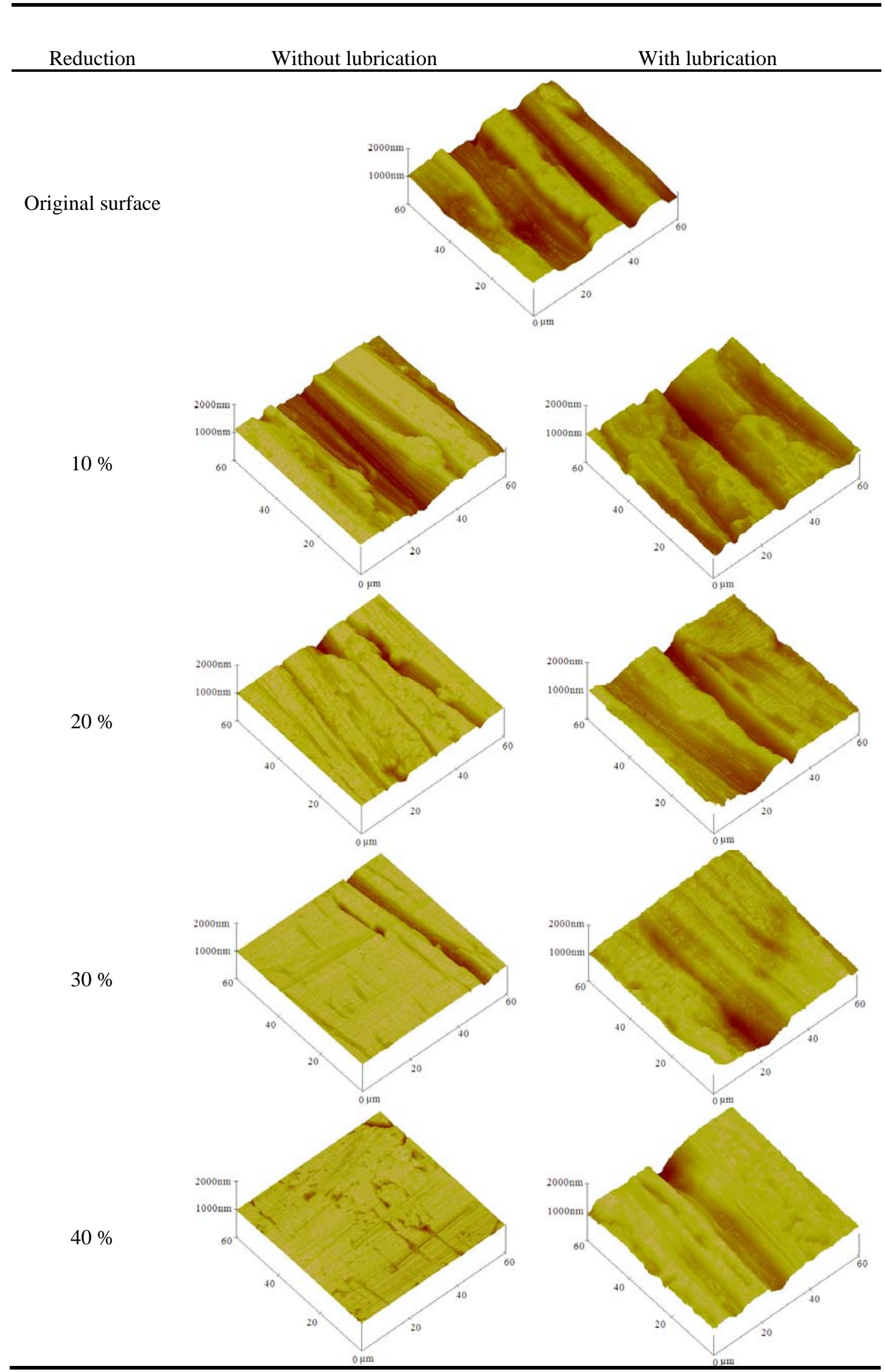




\subsection{Microstructure analysis}

Figs. 6a and $\mathrm{b}$ depict the inverse pole figure (IPF) and color mapping of microstructures measured by EBSD of FEGSEM (scale $200 \mu \mathrm{m}$ ). In Fig. 6, "RD, TD and ND” refer to three directions of the samples during the deformation process: "RD” means rolling direction, “TD” means Transverse direction and "ND” means normal direction. After annealing heat treatment, the microstructures of the sample are equiaxed grains with grain size of about $26 \mu \mathrm{m}$ (Fig. 6a). Most grains orientate in the orientation of [001], which is shown in red, while other grains orientate in the orientation of [101] as shown in green. The lamellar grain shapes which are thinner due to an extra reduction (60 \%) having a grain size smaller than 3.6 $\mu \mathrm{m}$ (Figs. 6b and c). The density of deep blue area increases significantly, in which the grain has [111] orientation. These areas also have a higher intensity of dislocation. In-grain shear bands are present and typically inclined at $15-35^{\circ}$ to the RD [22]. As a result of higher total dislocation density, the cold-uniaxial-planar-compressed sample contained a higher area fraction of in-grain shear bands. On the other hand, a few transgranular shear bands also appear in the area A, as shown in Fig. 6b, which is about 2-3 grain size distance away from the ND surface. Dislocation in this area is the most intense, which prompts an increase of internal energy of accumulated dislocation, and can thus overcome the obstacle of a grain boundary. Therefore, dislocation can spread across the grain boundaries. The original grains are broken into new grains. Practically, some HAGBs form in the area B (Fig. 6c). This confirms the result that the shear banding is preceded by the formation of obstacles to the homogeneous dislocation glide in the grain [23]. Under a reduction of $60 \%$, surface roughness of the sample decreases from original 930 to $192 \mathrm{~nm}$, and hardness increases from 30 to $57 \mathrm{HV}$. Furthermore, localized surface strain commences at this hardening area. This observation confirms the prediction of Hill [24] and Asaro [25] that the shear banding develops according to the instability in the macroscopic constitutive description of the inelastic deformation of hardening material. By using a different experimental method, Aicheler et al [26] also found that on the top surface of RFF (Radio-Frequency-heating Fatigue) FCC (face-centered cubic) copper, regions of [111] orientation have highly developed surface features, while regions of [100] do not have significantly developed surface features. Fig. 6c shows a few twinned area $\left(60^{\circ}<111>\Sigma 3\right.$ twin) of the same sample under a reduction of $60 \%$. According to the relevant theory, deformation twin can be analysed by the software Channel 5 from OXFORD. Area B is an obvious twinned area. Area B (Fig. 6c) and Area A (Fig. 6b) are almost similar. Therefore, the twinned area is not from annealed heat treatment (annealed twins), but generated from the compressing deformation (deformation twins). However, as the deformation twins have a small volume fraction, they will not have a volume effect on the texture evolution [27]. The influence of deformation twins on the development of surface asperity is also not significant. On the other hand, the hardening resulting from the transgranular shear band of the deformation twins is also not very large, and it only increases from $30 \mathrm{HV}$ (0 \%) to $57 \mathrm{HV}$ (60 \%).

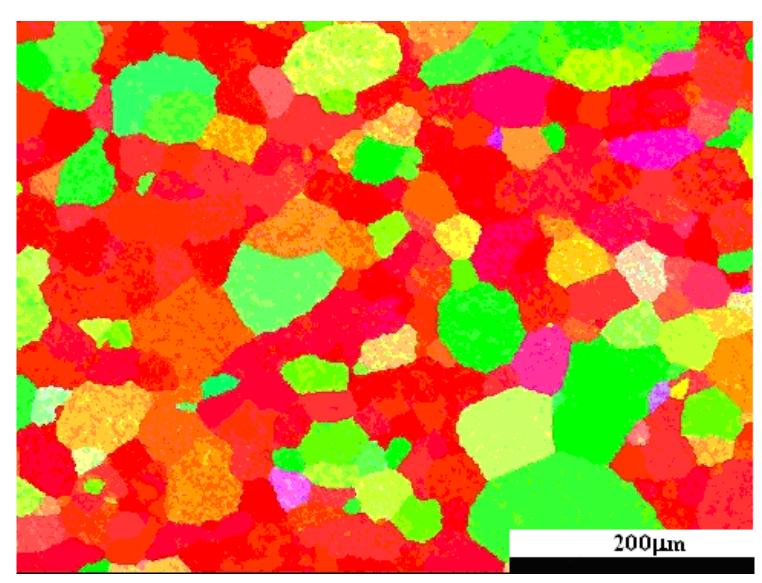

(a)

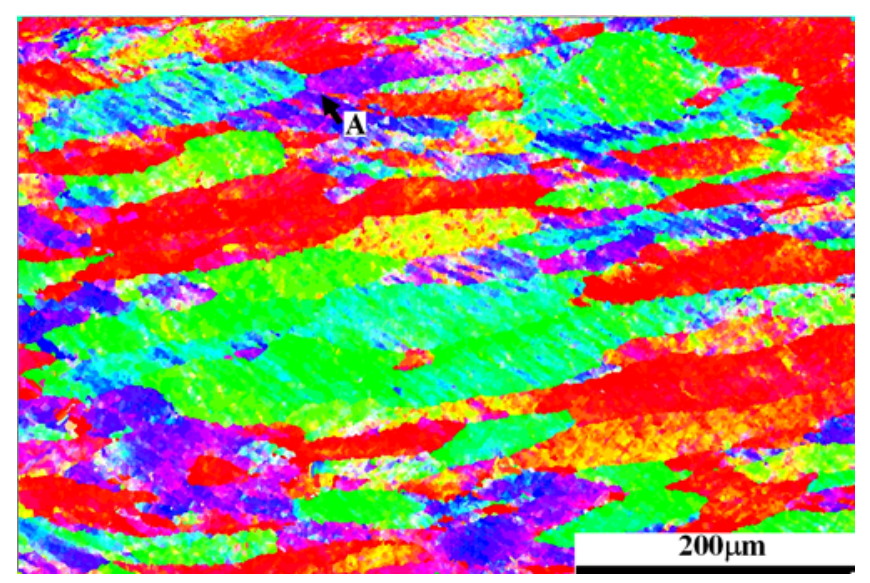

(b) 

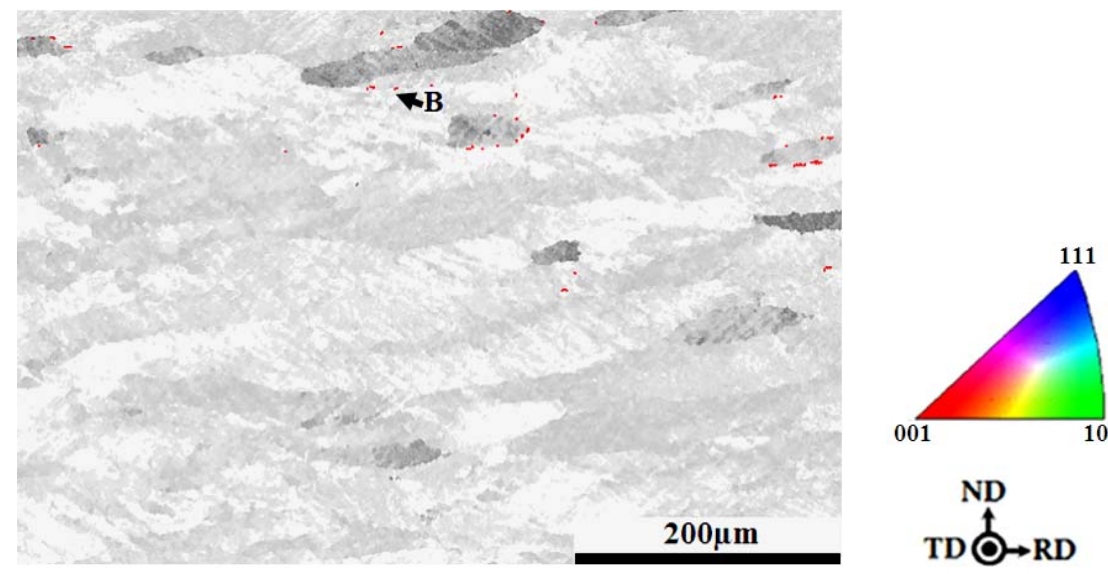

(c)

Fig. 6. Microstructures of FEG-SEM micrograph (a) annealed microstructure IFP, (b) aluminum IFP (cold reduction $60 \%$ ), (c) slip (Schmid factor) and $<111>60^{\circ}$ twin (cold reduction $60 \%$ ), LAGBs $\left(2^{\circ} \leq \theta<15^{\circ}\right)=$ grey, HAGBs $\left(15^{\circ} \leq \theta \leq 57.5^{\circ}\right)=$ black and $60^{\circ}<111>$ $\Sigma 3=$ red lines. Contour level: $0.5 \times$.

\subsection{Analysis of ODF figures}

ODF (Orientation Distribution Function) figures under different reductions in $\phi_{2}=0$ and $45^{\circ}$ sections describe the developing tendency of the deformed texture (Fig. 7). The Euler angles $\left(\phi_{1}, \Phi\right.$ and $\left.\phi_{2}\right)$ refer to three rotations, which performed in the correct sequence, transform the specimen coordinate system onto the crystal coordinate system [28]. The rotations are: $\phi_{1}$ about the normal direction $\mathrm{ND}$, transforming the transverse direction into TD' and the rolling direction RD into RD'; $\Phi$ about the axis RD' (in its new orientation); $\phi_{2}$ about ND'” (in its new orientation). Fig. 7a shows the texture component after annealed heat treatment. Orientation C (cubic orientation $\{001\}<100>$ ) has a high intensity in fully annealed sample. With an increase in reduction (at room temperature), the intensity of orientation $\mathrm{C}$ decreases, orientation $\mathrm{G}$ (Goss orientation $\{001\}<110>$ ) becomes obvious (Fig. 7b). When the reduction is about $40 \%$, intensity of Goss orientation $\{001\}<110>$ tends to be much stronger. Simultaneously, a few new texture component B (brass orientation $\{110\}<112>$ ) appears (Fig. 7c). As shown in Fig. 7d, Goss orientation has the highest intensity which is opposed to that of the cubic orientation, while brass orientation $\{110\}<112>$ becomes much stronger and obvious. This observation agrees with the cold rolling deformation of aluminium [29, 30]. Under a reduction of $60 \%$, a few transgranular shear bands appear that are resulted from deformation twins (Fig. 7a and c). Therefore, the formation of a shear band can be ascribed to the twinning of brass $\left(\mathrm{B},\{110\}<112>\right.$ ) [27]. Under $60 \%$ reduction, the samples have the lowest roughness $R_{a}$. Thus, it is obvious that the Goss orientation plays a major role in the development of surface feature (roughness $R_{a}$ ). Due to the small volume, the influence of brass orientation on the development of surface asperity will not be significant.
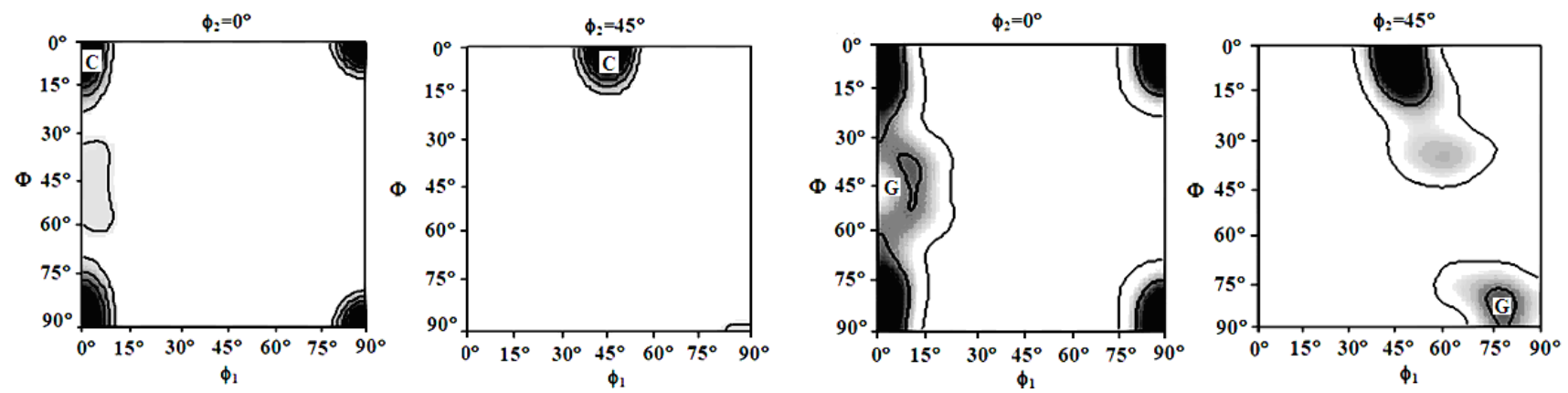

(a)

(b) 

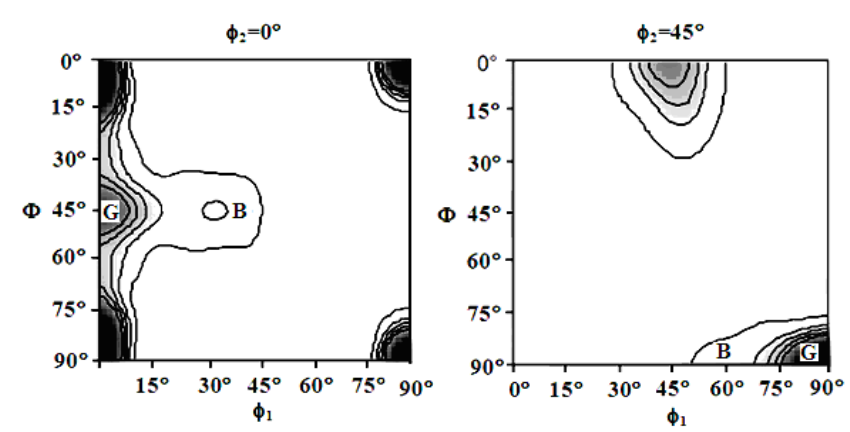

(c)

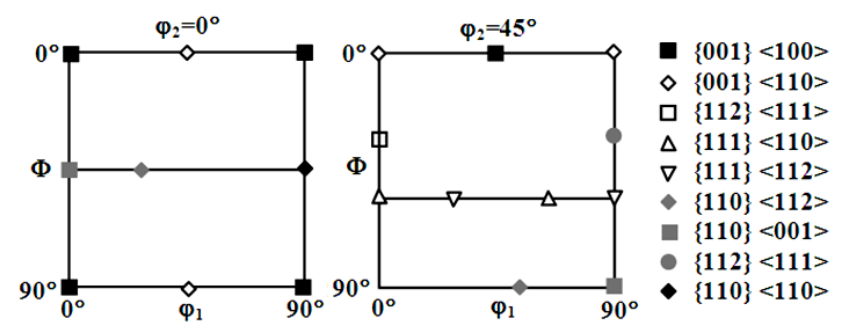

(e)
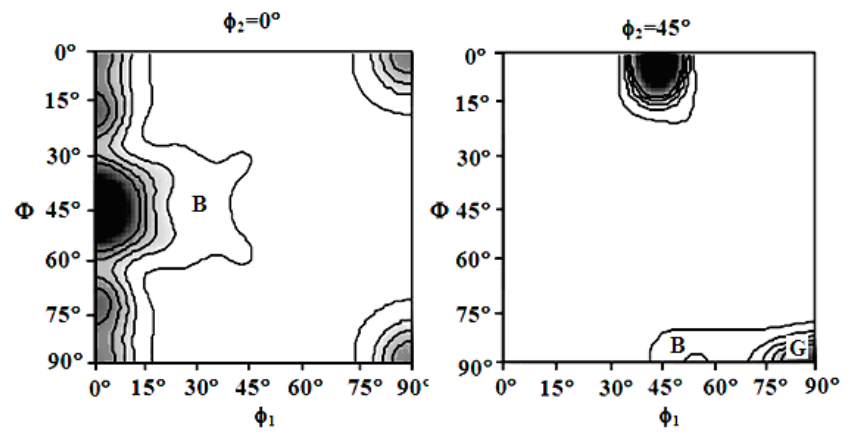

(d)

Fig. 7. $\phi_{2}=0^{\circ}$ and $45^{\circ}$ sections of (a) annealed sample ( $450{ }^{\circ} \mathrm{C}, 2 \mathrm{~h}$ ), (b) $20 \%$ cold planar compression, (c) $40 \%$ cold planar compression, (d) $60 \%$ cold planar compression, (e) main orientation representations . Contour levels: $0.5 \times$.

\subsection{Analysis of misorientations and CSL (Coincidence Site Lattice) boundaries}

Misorientations of different reductions are shown in Fig. 8a. Deformed grains possess lower internal misorientations and stored energy. Furthermore, deformation grains have large low-angle grain boundary (LAGB) populations and small deformation twin fractions $(\Sigma 3)$ [31]. Owing to the low deformation temperature (room temperature), the influence of recovering is not significant. Fig. $8 \mathrm{~b}$ shows the development of microstructure under different reductions. Due to the influence of an external load, a fraction of the deformed structure tends to decrease, while substructured $\left(\theta<2^{\circ}\right)$ fraction increases significantly from 1.3 to 18 . With an increase in reduction, a fraction of recrystallized structure almost keeps the same value. This observation indicates that at room temperature, there is no obvious dynamic recovery taking place in the deformed Al sample. Under small reductions, dislocation accumulates and tangles in grains. As a result, more substructures are formed in the deformed sample. $\Sigma 3\left(60^{\circ}\{111\}\right)$ and $\Sigma 7\left(38^{\circ}\{111\}\right)$ populations of newly nucleated and grown grains are shown in Fig. 8c. The population of the lower twin boundary is opposed to the growth of reduction. Here, twinning contributes insignificantly to the overall reduction in stored energy during deformation [32]. In-grain dislocation mobility and accumulation are the main sources of stored energy in deformation. In the surface asperity flattening process, Goss orientation contributes significantly to the surface asperity flattening (surface roughness). 


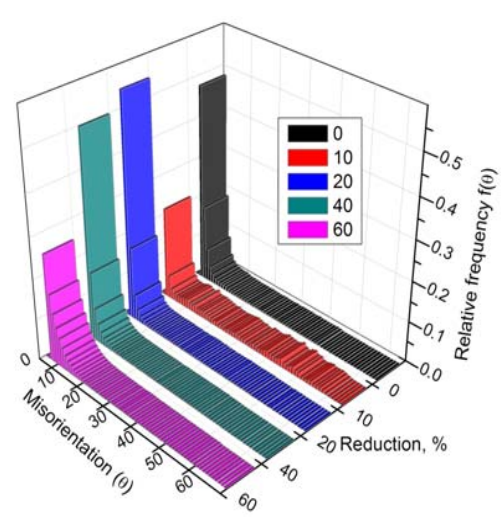

(a)

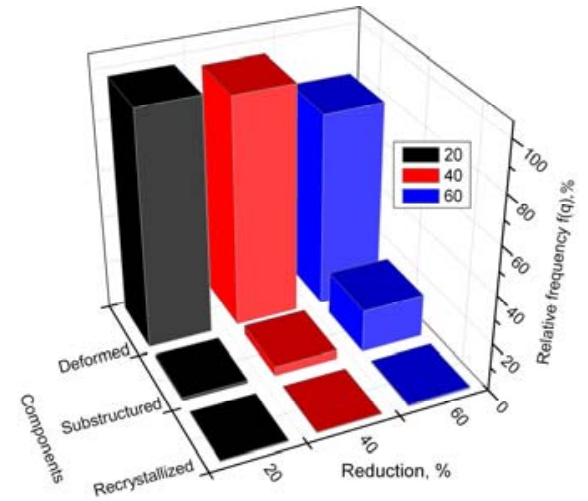

(b)

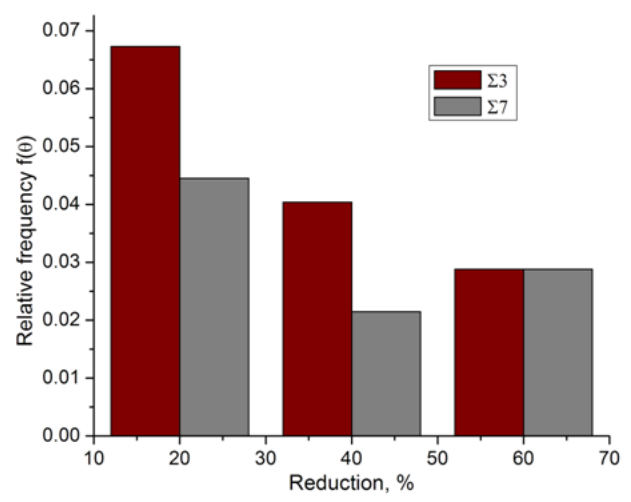

(c)

Fig. 8. Development of related parameters of ND surface: (a) misorientation, (b) microstructure components, (c) CSL (Coincidence Site Lattice) boundary of $\Sigma 3$ and $\Sigma 7$

\section{Conclusions}

In summary, surface asperity of sample tends to decrease, strain hardening increases with an increase of gauged reduction. Lubrication can constrain surface asperity flattening process. The dependency of a surface asperity feature on the development of surface (ND) microtexture was also analyzed, while accumulated dislocation and mobility contributed significantly to the misorientation by investigating the AFM and EBSD maps of cold uniaxial planar compressed (CUPC) sample. The results show that the orientated [111] grains play an important role in the development of surface asperity. In-grain slip (local stored energy) exists under overall reduction, however, its influence on surface asperity increases according to the increase of gauged reduction. The recovery and recrystallization under deformation are not significant. A few transgranular shear bands that resulted from the deformation twins of brass orientation were observed.

\section{Acknowledgments}

The authors are grateful to Dr. Azadiar A Gazder for help in the EBSD experiment; Hejie Li also appreciates the University of Wollongong for HDR scholarships. This work is supported by NSFC (Fund No. 51074051)

\section{References}

[1] Becker R. Effect of strain localization on surface roughening during sheet forming. Acta Materialia 1998;46:1385-401.

[2] Raabe D, Sachtleber M, Weiland H, Scheele G, and Zhao Z. Grain-scale micromechanics of polycrystal surfaces during plastic straining. Acta Materialia 2003;51:1539-60.

[3] M. Jain, D.J. Lloyd, and S.R. Macewen. Surface roughness and biaxial tensile limit strains of sheet aluminium alloys. International Journal of Mechanical Science 1996;38:219-32.

[4] Zhao Z, Ramesh M, Raabe D, Cuitino AM, and Radovitzky R. Investigation of three-dimensional aspects of grain-scale plastic surface deformation of an aluminium oligocrystal. Internationa Journal of Plasticity 2008;24:2278-97.

[5] Zhao Z, Radovitzky R, and Cuitino A. A study of surface roughening in fcc metals using direct numerical simulation. Acta Materialia 2004;52:5791-804.

[6] Osakada K, Oyane M. On the roughing of free surface in deformation process. Bulletin of JSME 1971;14:171.

[7] Tokizawa M, Yosikawa Y. The mechanism of lubricant trapping under the cold compression of metals. J. Japan. Inst. Met., 1973;37:19-25.

[8] Chen G, Shen H, Hu S, and Baudelet B. Roughening of the free surfaces of metalic sheets during stretching forming. Materials Science and Engineering A 1990;128:33-8.

[9] Stoudt MR, Ricker RE. The Relationship between grain size and the surface roughening behaviour of Al-Mg alloys. Metallurgical and Materials Transactions A 2002;33:2883-9. 
[10] Wilson WRD. Tribology in cold metal forming. Journal of Manufacturing Science 1997;119:695-8.

[11] Wilson WRD, Lee WM. Mechanics of surface roughening in metal forming process. Journal of Manufacturing Science Engineering 2001;123:279-83.

[12] Makinouchi A, Ike H, Murakawa M, and Koga N. A finite element analysis of flattening of surface asperities by perfectly lubricated rigid dies in metal working processes. Wear 1988;128:109-22.

[13] Sheu S, Wilson WRD. Flattening of workpiece surface asperities in metal forming. Proc. 11. N.A.M.R.C., 1983;172-78.

[14] Sutcliffe MPF. Surface asperity deformation in metal forming processes. International Journal of Mechanical Science 1988;11:847-68.

[15] Dieter GE. Mech. Metall. 3rd., McGraw-Hill, New York, NY 1986.

[16] Groche P, Schafer R, Justinger H, and Ludwig M. On the correlation between crystallographic grain size and surface evolution in metal forming processes. International Journal of Mechanical Science 2010;52:523-30.

[17] Groche P, Schafer R, and Henning M. Finite element calculation of surface Evolution considering grain size and crystallographic texture effects. Proceedings of the third international conference on tribology in manufacturing processes. ICTMP2007. Yokohama: Yokohama National University 2007;219-26.

[18] Li HJ, Jiang ZY, Wei DB, Han JT, and Tieu AK. Study on surface asperity flattening during uniaxial planar compression. Wear 2011;271:1778-84.

[19] Li HJ, Jiang ZY, Wei DB, Yan PJ, Tieu AL, and Han JT. Crystal plasticity finite element modeling of surface asperity flattening during uniaxial planar compression. International Conference on Tribology in Manufacturing Processes. 2010;397-406.

[20] Li HJ, Jiang ZY, and Wei DB. Crystal plasticity finite modelling of 3D surface asperity flattening in uniaxial planar compression. Tribology Letters 2012;46:101-12.

[21] Xie HB, Jiang ZY, Yuen WYD. Analysis of friction and surface roughness effects on edge crack evolution of thin strip during cold rolling. Tribology International 2011;44:971-9.

[22] Gazder A, Sanchez-Araiza M, Johnas J, and Pereloma E. Evolution of recrystallization texture in a 0.78 wt.\% Cr extra-low-carbon steel after warm and cold rolling. Acta Materialia 2011;59:4847-65.

[23] Kulkarni S, Starke E, Kuhlmann-Wilsdorf D. Some observations on deformation banding and correlated microstructures of two aluminium alloys compressed at different temperatures and strain rates. Acta Materialia 1998;46:5283.

[24] Hill R. Constitutive laws and waves in rigid/plastic solids. Journal Mech Phys Solids 1962;10:1.

[25] Asaro R. Geometrical effects in the inhomogeneous deformation of ductile single crystals. Acta Materialia 1979;27:445-53.

[26] Aicheler M, Sgobba S, Arnau-Izquierdo G, Taborelli M, Calatroni S, Neupert H, and Wuensch W. Evolution of surface topography in dependence on the grain orientation during surface thermal fatigue of polycrystalline copper. International Journal of Fatigue 2011;33:398-402.

[27] Gazder A, Saleh A, amd Pereloma E. Microtexture analysis of cold-rolled and annealed twinning-induced plasticity steel. Scripta Materialia 2011;65:561.

[28] Valerie R, and Olaf E. Introduction to Texture Analysis Macro texture, Micro texture and Orientation Mapping, Amsterdam, 2000.

[29] Mao W, Yang P, and Cheng L. Testing and Analyzing Principle of Material Texture, Beijing, 2008.

[30] Yang P. Application of Electron backscatter diffraction technique, Beijing, 2007.

[31] Huang J, Hsiao I, Wang T, and Lou B. Ebsd study on grain boundary characteristics in fine-grained Al alloys. Scripta Materialia 2000;43:218.

[32] Gindraux G, Form W. New concepts of annealing-twin formation in face-centered cubic metals. J. Inst. Mey. London 1973;101:85-92. 